\title{
Elastic-Wavefield Seismic Stratigraphy: A New Seismic Imaging Technology
}

\section{TECHNICAL PROGRESS REPORT}

\author{
Reporting Period Start Date: February 1, 2005 \\ Reporting Period End Date: April 30, 2005 \\ Principal Investigator (Author): Bob A. Hardage
}

Date Issued: May 6, 2005

DOE Cooperative Agreement No. DE-FC26- 03NT15396

\author{
Submitting Organization: \\ Bureau of Economic Geology \\ John A. and Katherine G. Jackson School of Geosciences \\ The University of Texas at Austin \\ University Station, Box X \\ Austin, TX 78713-8924
}




\section{Disclaimer}

This report was prepared as an account of work sponsored by an agency of the United States Government. Neither the United States Government nor any agency thereof, nor any of their employees, makes any warranty, express or implied, or assumes any legal liability or responsibility for the accuracy, completeness, or usefulness of any information, apparatus, product, or process disclosed, or represents that its use would not infringe privately owned rights. Reference herein to any specific commercial product, process, or service by trade name, trademark, manufacturer, or otherwise does not necessarily constitute or imply its endorsement, recommendation, or favoring by the United States Government or any agency thereof. The views and opinions of authors expressed herein do not necessarily state or reflect those of the United States Government or any agency thereof. 


\begin{abstract}
We have developed a numerical technique that will adjust 3-D S-wave seismic images so that they are depth equivalent to 3-D P-wave seismic images. The ability to make this type of P-SV to P-P depth registration is critical to our elastic wavefield seismic stratigraphy research because we now have higher confidence that depth-equivalent data windows are being used in the P-SV to P-P comparisons that we are making.
\end{abstract}




\section{Table of Contents}

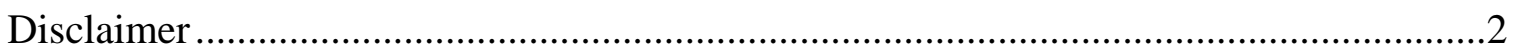

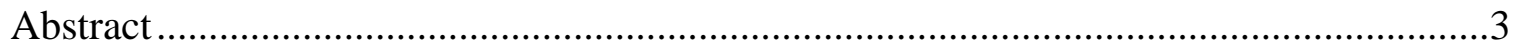

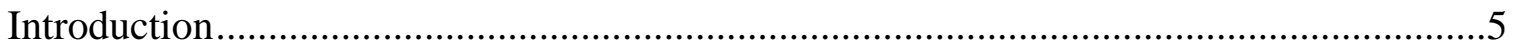

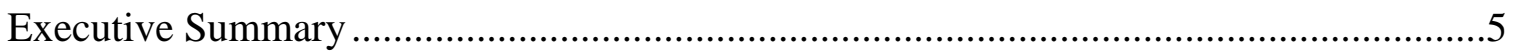

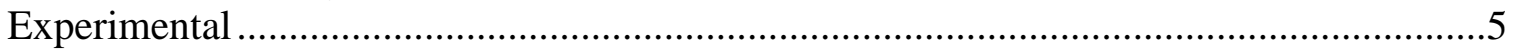

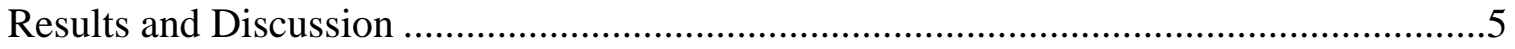

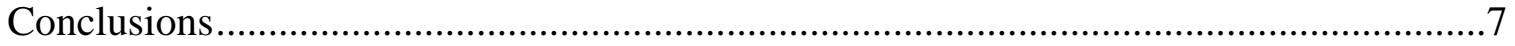

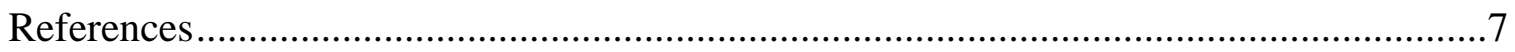

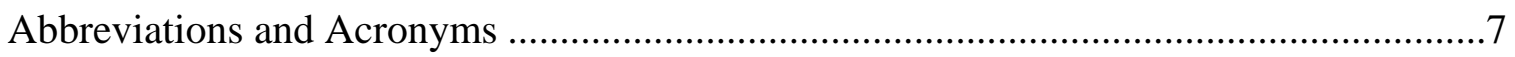

Figure

1. Example of P-P and P-SV images before and after depth equalization..................6 


\section{Introduction}

One of the greatest challenges in doing a correct elastic wavefield seismic stratigraphy analysis is that it is difficult to know that depth-equivalent seismic sequences and facies are being compared in P-P image space and P-SV image space. If an interpretation is done across a large vertical interval, the issue of defining the depth-equivalent boundaries of that interval in P-P and P-SV data is not so important. However, it is essential to define depth-equivalent P-P and P-SV data windows when a seismic stratigraphy analysis has to be done across a thin reservoir interval, which will be the application of this science that will be of greatest interest to explorationists. We show here a method that adds mathematical rigor to the problem of defining depth-equivalent data windows imaged by different modes of an elastic wavefield.

\section{Executive Summary}

One objective of our research has been to develop a methodology by which depthequivalent P-P and P-SV data windows can be defined and used for sequence and facies analyses. We first addressed this objective by developing a technique that worked for a single pair of synthetic P-P and P-SV seismic traces. After a few months of testing, we expanded that algorithm so that we could analyze 2-D P-P and P-SV profiles. In this last project period, we have advanced the methodology so that it works with 3-D multicomponent seismic data. With each application of the algorithm to real data, we have added better analysis methods and convergence steps and are now rather comfortable that we have a unique and valuable tool for assisting elastic wavefield seismic stratigraphy research.

\section{Experimental}

Experimental activity during this quarter consisted of developing and testing code that adjusts 3-D P-SV data to be depth equivalent to 3-D P-P data via a least-mean-squares optimization technique.

\section{Results and Discussion}

The mathematics of the depth-equalization algorithm that has been developed will not be described in this report. The methodology has been presented to, and accepted by, professional peers and can be reviewed in the paper published by Fomel and others (2003). We document in this report only one example that illustrates the accuracy and quality of the depth registration achieved in interpreting a 3C3D data volume. This example is illustrated as Figure 1. 

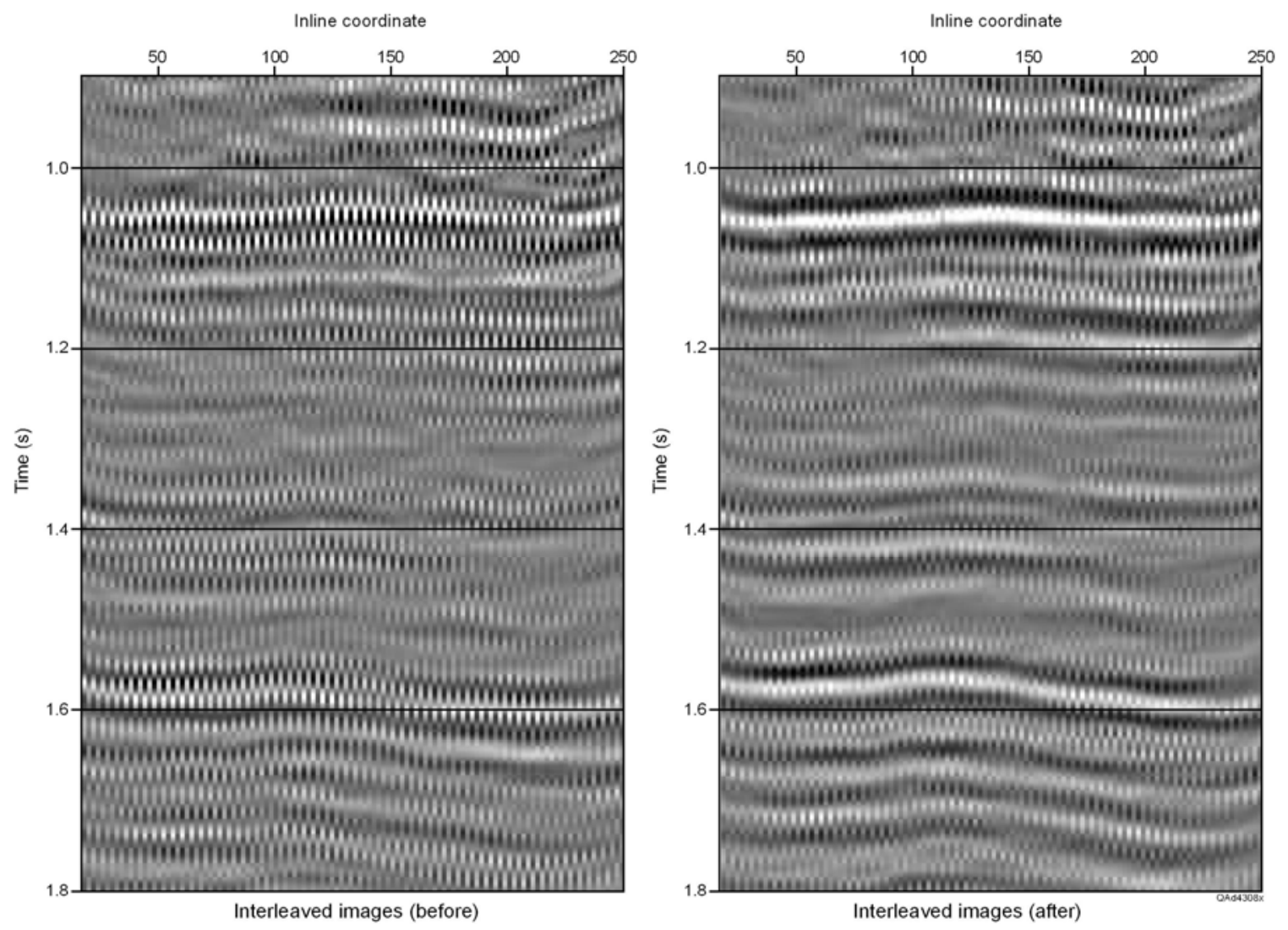

Figure 1. Examples of P-P and P-SV images before and after depth registration

The method requires that an interpreter first define a small number of depth-equivalent geological features (at least two or three) in both P-P and P-SV image space. Once these few control points are defined, they are used to do a first-order time warping to convert P-SV image time to P-P image time. This initial depth conversion is usually satisfactory for general comparisons of P-P and P-SV seismic sequences and facies, but it is not sufficient for detailed P-P and P-SV stratigraphic analysis of thin reservoir targets.

The data shown in the left panel of Figure 1 are P-P and P-SV data from one profile through a 3C3D data volume after the P-SV data have been time warped to P-P imagetime coordinates by one such first-order adjustment function. These adjusted data represent the type of P-SV to P-P depth registration that is commonly practiced across the industry. In this display, the P-P and P-SV data traces are interleaved to better illustrate the mismatch between the two images when a typical first-order time-warping correction is done. The data in the right panel are the same profile taken from the 3-D P-P and P-SV volumes after the volumes have been further depth registered according to our numerical procedure that uses a loosely constrained least-squares-optimization algorithm to adjust the images to an optimal match. There is now a better consistency between the interleaved traces, and we can calculate detailed seismic facies attributes in data windows that are quite thin, confident that the P-P and P-SV data span the same depth interval. 


\section{Conclusions}

Elastic wavefield seismic stratigraphy has been given a significant boost with the development of a numerical method that will allow P-P and P-SV images to be depth registered to high accuracy.

\section{References}

Fomel, S., Backus, M., DeAngelo, M., Murray, P., and Hardage, B., 2003, Multicomponent seismic data registration for subsurface characterization in the shallow Gulf of Mexico: Offshore Technology Conference, Paper OTC 15117, Houston, Texas, May 2003.

\section{Abbreviations and Acronyms}

None. 